\title{
Clinical outcomes of implant-retained mandibular overdentures using the bar and magnetic attachment systems: an up to 5-year retrospective study
}

\author{
Huan Zhou ${ }^{1 \#}$, Yang Jiao ${ }^{2,3 \#} \wedge$, Chu-Fan Ma ${ }^{1 \#}$, Chao Wang ${ }^{2}$, San-Jun Zhao ${ }^{1}$, Min Tian ${ }^{1}$, Franklin R. Tay ${ }^{4}$, \\ Ji-Hua Chen ${ }^{1}$
}

${ }^{1}$ National Clinical Research Center for Oral Diseases, State Key Laboratory of Military Stomatology, Shaanxi Key Laboratory of Stomatology, Department of Prosthodontics, School of Stomatology, the Fourth Military Medical University, Xi'an, China; ${ }^{2}$ Department of Stomatology, the $7^{\text {th }}$ Medical Center, Chinese PLA General Hospital, Beijing, China; ${ }^{3}$ Outpatient Department of PLA Macao Garrison, Macao, China; ${ }^{4}$ Department of Endodontics, the Dental College of Georgia, Augusta University, Augusta, GA, USA

Contributions: (I) Conception and design: H Zhou, Y Jiao, CF Ma; (II) Administrative support: JH Chen; (III) Provision of study materials or patients: JH Chen; (IV) Collection and assembly of data: C Wang, M Tian, FR Tay; (V) Data analysis and interpretation: SJ Zhao; (VI) Manuscript writing: All authors; (VII) Final approval of manuscript: All authors.

\#These authors contributed equally to this work and should be considered co-first authors.

Correspondence to: Yang Jiao, PhD. Department of Stomatology, the 7th Medical Center, Chinese PLA General Hospital, No. 5, Nanmencang, Dongsishitiao Street, Dongcheng District, Beijing 100700, China. Email: jiaoyang1989731@163.com; Ji-Hua Chen. Professor, National Clinical Research Center for Oral Diseases, State Key Laboratory of Military Stomatology, Shaanxi Key Laboratory of Stomatology, Department of Prosthodontics, School of Stomatology, the Fourth Military Medical University, No. 145, Changle West Road, Xi'an 710032, China. Email: jhchen@fmmu.edu.cn.

Background: Implant-retained mandibular overdentures (IODs) represent an effective and reliable treatment modality for edentulous patients. The present retrospective study compared the clinical outcomes of IODs using bar attachment (BA) system with those using magnetic attachment (MA) system after functioning for up to 5 years.

Methods: Human subjects treated with IODs between 01-01-2010 and 12-31-2014 were identified from patient records. Of the 54 subjects who met the inclusion criteria, 48 subjects including 26 treated with BAIODs and 22 with MA-IODs (96 mandibular implants) were recruited for the study. The implant units and prostheses were evaluated individually for peri-implant health. Prosthetic complications and maintenance during follow-up were recorded. The subjects responded to the visual analog scale (VAS) and the Oral Health Impact Profile questionnaires for evaluation of patient satisfaction and oral health-related quality of life (OHRQoL).

Results: The survival rates of the implants and prostheses were $96.9 \%$ and $95.8 \%$, respectively, over a mean observation period of 48 11.3 (range, 13-64) months. Peri-implant probing depth (PPD) and plaque index (PI) were significantly better for the MA group compared with the BA group $(\mathrm{P}<0.05)$, while marginal bone loss $(\mathrm{MBL})$ and sulcus bleeding index $(\mathrm{SBI})$ showed no significant differences $(\mathrm{P}>0.05)$. Prosthetic complications and maintenance were attachment-dependent. Most recruited subjects were satisfied with their prostheses. There was no statistically significant difference regarding general patient satisfaction or OHRQoL between the two groups $(\mathrm{P}>0.05)$. Nevertheless, patients complained that the BA-IODs were significantly more difficult to clean than the MA-IODs $(\mathrm{P}<0.05)$.

Conclusions: IODs have an ideal medium-term outcome irrespective of the attachment design. It is recommended that oral hygiene instructions and regular clinical examination be given to subjects wearing IODs.

\footnotetext{
^ ORCID: 0000-0002-1844-4246.
} 
Keywords: Clinical outcome; implant; mandibular overdentures; patient satisfaction; quality of life

Submitted Mar 16, 2020. Accepted for publication Sep 14, 2020.

doi: 10.21037/atm-20-2531

View this article at: http://dx.doi.org/10.21037/atm-20-2531

\section{Introduction}

Population aging has resulted in an upsurge of the number and proportion of edentulous individuals. It has been estimated that over $20 \%$ of the elderly population suffers from edentulism (1). The retention and stability of complete dentures are two important factors in successful prosthodontic rehabilitation of the edentulous jaw (2). Continuous resorption of the alveolar ridge occurs after the loss of all teeth. This subsequently results in atrophy of the alveolar ridge, especially for the mandibular alveolar ridge. Although some edentulous patients can adapt to their complete dentures, many patients are dissatisfied with the retention and fit of their mandibular dentures because of the lack of adequate support (3). It has been reported that more than $50 \%$ of the complete denture wearing subjects complain of poor oral function, oral pain and discomfort (4). Different methods have been used to provide support for complete dentures, including use of soft liners, cushions and denture adhesives, with limited success (5).

Implant-retained mandibular overdentures (IODs) represent an effective and reliable therapy for the edentulous; IODs address the problems of insufficient stability and retention associated with mandibular complete dentures $(6,7)$. Clinical studies investigating short-term and long term outcomes showed that IODs have higher survival rates, improved oral function, and better patient satisfaction and oral health-related quality of life (OHRQoL) compared with conventional complete dentures $(8,9)$. Furthermore, IODs significantly improve objective chewing ability and maximum occlusal force and provide a stable centric occlusion for edentulous patients (10). Different IOD attachment systems such as bar and magnetic attachments (MAs) are commercially available (11). The bar attachment (BA) is the most commonly used retention design. It relies on mechanical embedment of the overdenture between bar retainers using clip attachments, but it has disadvantages such as oral hygiene problems $(12,13)$. The MA is another useful design for reducing lateral displacement forces on the implants because the magnetic field does not resist horizontal forces (11). Evaluations of clinical outcome for
IODs often involve objective examination of peri-implant health and subjective survey of subject satisfaction. Although clinical success with IODs has been reported using both attachment mechanisms, biological complications regarding peri-implant tissue health continue to be a major problem (14). These conditions are highly relevant for the success and longevity of prostheses. The subject's overall satisfaction of treatment comfort and function is a crucial factor that accounts for treatment success. To date, several studies have independently compared peri-implant tissue conditions, prosthetic complications and maintenance, patient satisfaction and OHRQoL among different IOD attachment types (15-17). However, a comprehensive evaluation of all these issues is lacking.

Accordingly, the objective of the present retrospective study was to investigate the peri implant tissue conditions, prosthetic complications and maintenance, patient satisfaction and OHRQoL in subjects treated with BA-IODs and MA-IODs after functioning for up to 5 years. The null hypothesis tested was that there is no difference between IOD attachment types with respective to peri-implant health and subject satisfaction. We present the following article in accordance with the STROBE reporting checklist (available at http://dx.doi.org/10.21037/atm-20-2531).

\section{Methods}

\section{Study design}

The present single-center, retrospective cohort study included 54 recruited subjects who were prescribed mandibular IODs by the Department of Prosthodontics, School of Stomatology, the Fourth Military Medical University, Xi'an, China between 01-01-2010 and 12-312014 for treatment of mandibular edentulism. The inclusion criteria included no apparent jaw malocclusion (i.e., Class II or Class III jaw relation), no intraoral soft and hard tissue pathology, no uncontrolled or progressive periodontitis, and no uncontrolled systematic diseases such as infectious or metabolic diseases, cardiovascular disease, hypertension, diabetes and immunodeficiency. Additionally, subjects who 
underwent oral or intravenous bisphosphonate therapy, anticoagulant therapy or reported a history of head/neck radiation that contraindicates implant treatment were also excluded. Although smoking was not an exclusion criterion, smokers were asked to refrain from smoking during the study period. All forms of opposing dentitions were accepted as long as they were in satisfactory conditions.

The recruited subjects were explicitly informed of the intent and duration of the study. Six subjects were excluded from the study during the follow-up period for reasons not related to the study: one subject was deceased, two subjects refused to participate in the study because of their unwillingness to abide by the smoking cessation request, and three subjects could not be contacted because of phone number changes. Forty-eight subjects (21 males and 27 females with a mean age of 64.7 years) were included in the study and invited for interview and clinical examination. The study was conducted in accordance with the Declaration of Helsinki (as revised in 2013). The study protocol was reviewed and approved by the Institutional Review Board of Stomatological Hospital of Fourth Military Medical University (approval number: IRB REV-2016036). Informed consent was received from all the patients.

\section{Surgical and prosthodontic procedures}

Written informed consent was obtained from all patients. Radiographic evaluation in the form of cone-beam computed tomography (Sirona, Bensheim, Germany) was obtained for pre operative evaluation prior to treatment. Each subject was treated under local anesthesia, and two Straumann implants (Straumann, Freiburg, Germany) were installed in the canine region of the mandible following recommendations provided by the manufacturer. The implants were selected according to the available bone height and had a diameter of 3.3 or $4.1 \mathrm{~mm}$ and a length of up to $14 \mathrm{~mm}$. An artificial bone substitute material (Bio-Oss, Geistlich, Switzerland) and collagen membrane (Bio-Gide, Geistlich) were used to assist implant placement in patients with insufficient bone volume.

A complete denture was fabricated at two weeks postsurgery. The intaglio surface of the denture, around the healing abutment, was relieved for fitting the abutment head. Radiographic examination was performed after a healing period 3 to 6 months to confirm that implant placement had been successful. The selection of attachment type was made according to the patient's demands and conditions of the jaw. Each patient received a two-implant retained mandibular IOD. Of those overdentures, 26 were BA-IODs, and 22 were MA-IODs. Each patient was given oral hygiene instructions after prosthodontic treatment.

\section{Clinical examination}

Information was obtained on oral hygiene habits for the implants and prostheses prior to clinical examination. Implant survival was defined as an implant loaded and in use without clinical symptoms such as pain, mobility or infection (18). The implant survival rate was defined as the number of successful implants/the total number of implants. The following clinical parameters were recorded: plaque index (PI), peri-implant probing depth (PPD), sulcus bleeding index (SBI), marginal bone loss (MBL) and mucosal hyperplasia (MH). The PI was scored at four sites around each implant, according to Silness and Löe: $0=$ no plaque, $1=$ plaque on probing, $2=$ visible plaque, and $3=$ abundant plaque. For each implant, one PI value was calculated based on the average of the four values (19). The PPD was measured at six sites for each implant, and the highest value for each implant was recorded. The SBI was scored at four surfaces around the implants: $0=$ no bleeding and $1=$ bleeding. For each implant, one SBI value was calculated based on the average of the four values. The MBL was recorded using standardized long-cone periapical radiographs. All the images were scanned and analyzed using an image analysis software (Digimizer, MedCalc software, Ostend, Belgium). Specifically, the implant length was used as reference, and the MBL was measured at the mesial and distal aspects of an implant from the implant shoulder to the first visible bone contact along the implant axis. The mesial and distal scores were averaged (20,21). $\mathrm{MH}$ around the implants and abutments was recorded as none, moderate or abundant (22). Prosthetic complications and maintenance during the follow-up were also recorded.

\section{Subject satisfaction}

Recruited subjects responded to the visual analog scale (VAS) and the Oral Health Impact Profile-14 questionnaire for evaluation of subject satisfaction and OHRQoL, respectively. The VAS questionnaire was used for rating a subject's satisfaction with the IOD in the following eight areas: general satisfaction, retention, speech, esthetics, pain, chewing, comfort and ease of cleaning. Subjects were instructed to place a vertical line on the $100 \mathrm{~mm}$ scale to indicate their degree of satisfaction, with the left end [0] 


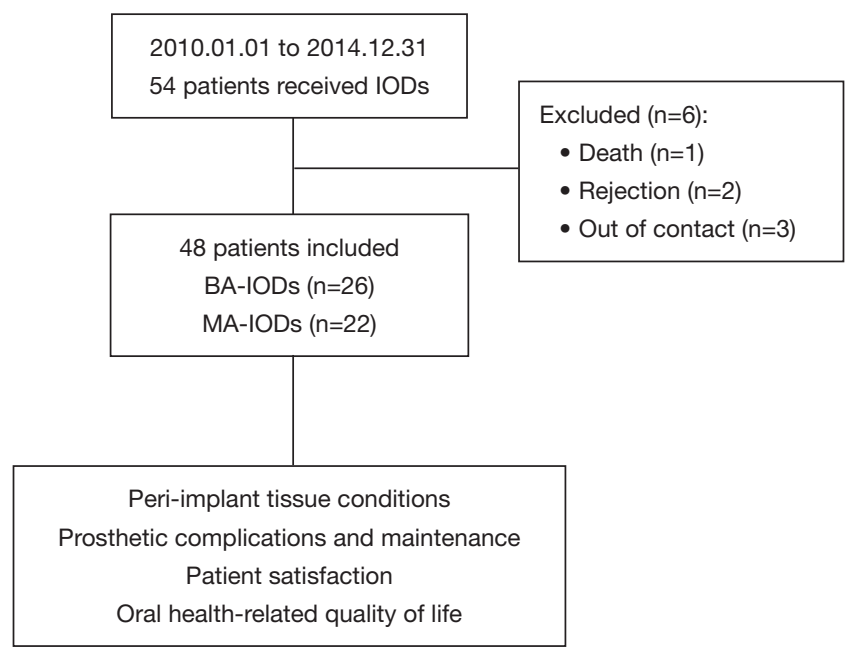

Figure 1 Flowcharts of enrolled patients. BA, bar attachment; IOD, implant-retained overdenture; MA, magnet attachment.

indicating completely unsatisfied, and the right end [100] indicating completely satisfied.

The Oral Health Impact Profile-14 is the most validated questionnaire for measuring OHRQoL. The questionnaire includes 7 items: functional limitation, physical pain, psychological discomfort, physical disability, psychological disability, social disability and handicap. Each subject was asked to record his/her responses on a five-point Likert scale $(0=$ never, $1=$ hardly ever, $2=$ occasionally, $3=$ fairly often, and $4=$ very often). The total score was calculated by adding the scores of the 7 items, and it ranged from 0 and 28 , with a lower score indicating better OHRQoL.

\section{Statistical analysis}

The SPSS 18.0 statistical analysis package (SPSS Inc., Chicago, USA) was used for statistical analysis. Data sets were examined for their normality (Shapiro-Wilk test) and homogeneity of variance (modified Levene test) prior to the use of parametric statistical procedures. If these assumptions appeared to be violated, analyses were performed using nonparametric statistical methods. The Mann-Whitney rank sum test was used to evaluate the influence of oral hygiene habits on PI. The Kruskal-Wallis $\mathrm{H}$ test for multiple independent samples was used when the grouping variable was more than 3 . The nonparametric Nemenyi post hoc test was used for pairwise comparisons. Factorial analysis and one-factor analysis of variance was used for comparison of PI, PPD, SBI and MBL. Data acquired for MH and status of the prostheses were not statistically analyzed. One-factor analysis of variance was used for comparison of patient satisfaction and OHRQoL. For all evaluations, statistical significance was preset to $\alpha=0.05$.

\section{Results}

\section{Sample description}

A flowchart of the recruited subjects is presented in Figure 1, and subject demographics are listed in Table 1. For the opposing dentition, 26 subjects had maxillary complete dentures, 11 had tooth-supported removable partial dentures, 9 had IODs, and 2 had their own teeth. Three implants in two subjects were dropped from the study, resulting in two IOD failures. Over a mean observation period of $48 \pm 11.3$ (range, 13-64) months, the survival rates of the implants and prostheses were $96.9 \%$ (93/96) and 95.8\% (46/48), respectively. The three failed implants were replaced, and healing was uneventful.

\section{Clinical outcomes}

The frequency of daily cleaning of the dentures varied from once a day to more than three times a day (Table 2). Those subjects who cleaned their dentures three times a day or more demonstrated better outcomes with a lower PI $(\mathrm{P}<0.05)$.

For the peri-implant variables, significantly better results were recorded for PPD and PI in the MA group than the BA group $(\mathrm{P}<0.05)$. However, no significant differences were identified between subjects wearing MA-IODs and those wearing BA-IODs with respect to SBI and MBL 
Table 1 Subject demographics

\begin{tabular}{lc}
\hline Characteristics & Number (\%) \\
\hline Age & $7(14.6)$ \\
$40-54$ & $18(37.5)$ \\
$55-64$ & $23(47.9)$ \\
$\geq 65$ & \\
Sex & $21(43.8)$ \\
Male & $27(56.2)$ \\
Female & \\
Opposing dentition & $26(54.2)$ \\
Complete denture & $11(22.9)$ \\
Removable partial denture & $9(18.9)$ \\
Implant-retained maxillary overdentures & $2(4.2)$ \\
Natural teeth &
\end{tabular}

( $\mathrm{P}>0.05$; Table 3). Although $\mathrm{MH}$ was observed in both groups of recruits, subjects in the BA group ( 9 with slight hyperplasia and 3 with abundant hyperplasia) appeared to have more severe hyperplasia than those in the MA group (2 with slight hyperplasia; Table 4). For the bone augmentation procedure and implant parameters, there were no statistically significant differences in the clinical outcomes between the two groups in terms of PPD, SBI, PI and MBL ( $\mathrm{P}>0.05$; Table S1).

With respect to the status of the prostheses (Table 5), loosening of the attachment screw $(25 \%)$ and inactivation of the bar-clip (25\%) were the most frequently encountered complications for BA-IODs. Attachmentdependent complications observed in the MA group were predominantly associated with replacement of magnets (27.27\%). For maintenance of the prostheses, both groups require denture relining ( $21.4 \%$ for $\mathrm{BA}$ and $36.4 \%$ for $\mathrm{MA}$ ) and occlusal adjustment (17.9\% for BA and $27.3 \%$ for MA).

\section{Subjective evaluation of functionality and aesthetics}

Most recruits were 'satisfied' with the functionality and aesthetics of their prostheses (general satisfaction: $88.9 \pm 7.6$ for the BA group and $89.1 \pm 8.0$ for the MA group out of a maximum score of 100; Table 6). There was no difference in the general satisfaction scores between the two attachment systems $(\mathrm{P}>0.05)$. Significantly better outcomes were identified for the MA-IODs with respect to the ease of cleaning $(\mathrm{P}<0.05)$. Better scores were recorded for the MA-IODs in terms of speech, esthetics, pain and comfort, although there were no significant differences between the two groups. Although the subjects considered the retention and chewing function of the BA-IODs to be better, there was no significant difference between the two attachment systems.

\section{Analysis of the prosthetic well-being}

The Oral Health Impact Profile-14 scores for all the items were not significantly different between the BA-IODs and MA-IODs $(\mathrm{P}>0.05$; Table 7$)$. There were no significant differences between the groups of recruits in terms of 'functional limitation' (BA vs. MA: $0.69 \pm 0.68$ vs. $0.68 \pm 0.65$ ), 'physical pain' $(0.62 \pm 0.64$ vs. $0.59 \pm 0.67)$, 'psychological discomfort' ( $0.77 \pm 0.75$ vs. $0.86 \pm 0.47)$, 'physical disability' $(1.65 \pm 1.09$ vs. $1.55 \pm 1.05)$, 'social disability' $(1.04 \pm 1.00$ vs. $1.23 \pm 1.11)$, 'psychological disability' $(1.19 \pm 0.98 v s$. $1.05 \pm 1.25)$ and 'handicap' $(1.27 \pm 1.19$ vs. $0.91 \pm 0.97)$.

\section{Discussion}

Implant-retained overdentures have rapidly become the standard of care for prosthodontic treatment of edentulous patients to improve the retention and stability of complete dentures. The present retrospective cohort study comprehensively evaluated the clinical outcomes of IODs and examined the effects of two IOD attachment systems on subject well-being. The inclusion and exclusion criteria and the analysis of variables followed the benchmarks adopted in previous studies. The present sample size compared favorably to those of other studies with similar objectives and methods (11,15-17).

The survival rate of the prostheses was $95.8 \%$ in the present study after a follow-up period of nearly 5 years. The result is comparable to the 20 -year survival rate of $95.5 \%$ in a previous retrospective study of 425 IODs (23). Another clinical study reported a $97.7 \%$ survival rate after $5-19$ years of clinical function (24). These findings indicate that IOD is an effective and reliable treatment modality for edentulous patients with minimal risks during the observation period.

The MA system showed significantly better results than the BA system in terms of peri implant health. Although there was no difference in SBI, both the PI and PPD scores of the recruited subjects were significantly lower in the MA group. These data suggest that the BA system accumulates more plaque biofilms than the MA system. The higher PI 
Table 2 Plaque index (PI) based on the number of daily cleaning

\begin{tabular}{lccc}
\hline Daily cleaning & Number & Mean \pm SD & P value \\
\hline Once a day & 13 & $1.79 \pm 0.84$ & $0.023^{*}$ \\
Twice a day & 26 & $1.13 \pm 0.65$ & $1.05 \pm 0.39$ \\
$\geq$ three times a day & 9 & & \\
\hline
\end{tabular}

*, significantly different $(\mathrm{P}<0.05)$. SD, standard deviation.

Table 3 Peri-implant health conditions

\begin{tabular}{lccc}
\hline Index & BA & MA & P value \\
\hline PI & $1.29 \pm 0.95$ & $0.69 \pm 0.64$ & $0.02^{*}$ \\
PPD & $2.90 \pm 0.91$ & $2.30 \pm 0.80$ & $0.04^{*}$ \\
SBI & $0.10 \pm 0.27$ & $0.08 \pm 0.22$ & 0.85 \\
MBL & $1.22 \pm 0.68$ & $1.32 \pm 0.76$ & 0.82 \\
\hline
\end{tabular}

Values are means \pm standard deviations. * , significantly different $(\mathrm{P}<0.05)$. $\mathrm{P}$ values labeled with asterisks are significantly different $(\mathrm{P}<0.05)$. $\mathrm{BA}$, bar attachment; MA, magnet attachment; MBL, marginal bone loss; PI, plaque index; PPD, peri-implant probing depth; SBI, sulcus bleeding index.

Table 4 Mucosal hyperplasia ${ }^{\dagger}$

\begin{tabular}{lccc}
\hline Variables & BA & MA & Total \\
\hline None & 14 & 20 & 34 \\
Slight & 9 & 2 & 11 \\
Abundant & 3 & 0 & 3 \\
Total & 26 & 22 & 48 \\
\hline
\end{tabular}

${ }^{\dagger}$, no statistical analysis was performed. BA, bar attachment; MA, magnet attachment.

scores in the subjects wearing BA-IODs may be attributed to their unique design, which makes it difficult for patients to clean the tissues around the implant (18). In contrast, MA-IODS are easily cleanable, which results in less plaque accumulation around the implants (25). Lehmann et al. reported that the association of a higher PPD score with greater plaque accumulation and pathogenic microflora with peri-implantitis (12). Recent studies showed that neither implant type nor attachment design influences alveolar bone loss in patients with mandibular IODs (26). For example, the mean MBL was comparable among the different types of IODs in a 10-year randomized controlled clinical trial (27). In the present study, no significant difference was observed for the mean MBL between the BA group and the MA group; the result was consistent with a previous study (27). Both attachment systems recorded values that are reflective of a healthy periodontal status, which is crucial for the longterm success of IOD treatment.

In the present study, more extensive $\mathrm{MH}$ was recorded in the BA group. The presence of inflammation around the mucosa in patients with BA-IODs may be attributed to insufficient space from the gingiva to the upper bar for proper cleaning. Kuoppala et al. reported the same finding that more $\mathrm{MH}$ was clinically observed with the BA system than with other attachment systems (28). Previous studies demonstrated that the MA system is not only easier to clean but also has less $\mathrm{MH}$ compared with other attachment systems (29). This is an important consideration in the treatment of patients who have limited physical capacity to maintain a high standard oral hygiene or who suffer from debilitating diseases such as arthritis. The present study also demonstrated that subjects who maintained a high level of oral hygiene (daily cleaning) had healthier soft tissues around the implants. Besides, $\mathrm{MH}$ was most extensive in those subjects who wore their overdentures during sleep. Hence, it is prudent to stress that dentists provide patients with detailed hygiene instructions during denture delivery and maintenance appointments.

The intervention/patient ratio of the BA-IODs (28/26) was higher than that of the MA-IODs (22/22). Attachment screw loosening and bar-clip inactivation were the most frequently encountered complications for BA-IODs, and magnet replacement was the most frequently encountered 
Table 5 Prosthetic complications and maintenance ${ }^{\dagger}$

\begin{tabular}{lcc}
\hline Variables & BA & MA \\
\hline Loosing of attachment screw & 7 & 0 \\
Fracture of the bar & 2 & 0 \\
Exchange of magnet & 0 & 0 \\
Activation of clip & 7 & 2 \\
Fracture of the denture & 1 & 8 \\
Reclining of the denture & 6 & 6 \\
Occlusal adjustments & 5 & 22 \\
Total number & 28 & $1.0(22 / 22)$ \\
Interventions/patient & $1.07(28 / 26)$ & \\
\hline
\end{tabular}

${ }^{\dagger}$, no statistical analysis was performed. BA, bar attachment; MA, magnet attachment.

Table 6 Visual analog scale (VAS)

\begin{tabular}{|c|c|c|c|}
\hline Variables & Group & Mean \pm SD & $P$ value \\
\hline General satisfaction & MA & $89.1 \pm 8.0$ & \\
\hline \multirow[t]{2}{*}{ Retention } & BA & $88.3 \pm 8.6$ & 0.425 \\
\hline & MA & $86.9 \pm 7.3$ & \\
\hline Speech & MA & $90.3 \pm 7.6$ & \\
\hline \multirow[t]{2}{*}{ Esthetics } & BA & $89.5 \pm 6.6$ & 0.619 \\
\hline & MA & $90.7 \pm 6.9$ & \\
\hline Pain & BA & $85.0 \pm 7.9$ & 0.527 \\
\hline Chewing & MA & $82.3 \pm 11.4$ & \\
\hline \multirow[t]{2}{*}{ Comfort } & BA & $80.7 \pm 9.4$ & 0.992 \\
\hline & MA & $81.0 \pm 8.6$ & \\
\hline \multirow[t]{2}{*}{ Ease of cleaning } & BA & $83.0 \pm 7.9$ & $<0.001^{\star}$ \\
\hline & MA & $94.7 \pm 5.0$ & \\
\hline
\end{tabular}

Values are means \pm standard deviations. *, significantly different $(P<0.05)$. $P$ values labeled with asterisks are significantly different $(P<0.05)$. BA, bar attachment; MA, magnet attachment.

complication for MA-IODs. These maintenance interventions are related to the unique design of the attachment systems, as reported by other investigators (11). The mechanical components of the BA system, such as bar retainers and clip attachments, are easily worn down during insertion and removal of the overdenture. For the MA system, attachment forces generated by the magnets decreased over time, and it was likely that one or more magnets will have to be replaced. Because the MA system does not require a straight insertion path, 
Table 7 Oral Health Impact Profile-14

\begin{tabular}{|c|c|c|c|c|}
\hline Variables & Group & Mean & SD & $P$ value \\
\hline Functional limitation & MA & 0.68 & 0.65 & \\
\hline \multirow[t]{2}{*}{ Physical pain } & BA & 0.62 & 0.64 & 0.854 \\
\hline & MA & 0.59 & 0.67 & \\
\hline Psychological discomfort & MA & 0.86 & 0.47 & \\
\hline \multirow[t]{2}{*}{ Physical disability } & BA & 1.65 & 1.09 & 0.746 \\
\hline & MA & 1.55 & 1.05 & \\
\hline Psychological disability & BA & 1.19 & 0.98 & 0.430 \\
\hline Social disability & MA & 1.23 & 1.11 & \\
\hline \multirow[t]{2}{*}{ Handicap } & BA & 1.27 & 1.19 & 0.274 \\
\hline & MA & 0.91 & 0.97 & \\
\hline
\end{tabular}

Values are means \pm standard deviations. $P$ values labeled with asterisks are significantly different $(P<0.05)$. BA, bar attachment; MA, magnet attachment.

it has the unique advantage of being more tolerant to implant direction and positioning (30). Newer versions of magnets with more durable and strong housings that are manufactured using laser-welding techniques are expected to improve attachment performance and prevent magnet corrosion (11). Denture relining and occlusal adjustment were frequently required for both attachment systems in the present investigation, as reported previously (31). Submucosal alveolar bone resorption occurs after several years of denture loading. The space created between the resorbed bone and the denture acrylic creates torque on the abutment during function, which adversely deteriorates implant osseointegration. Rebasing the overdentures is necessary to prolong the functionality of the implants and to ensure patient comfort. For this reason, occlusal adjustment is often required during the adaptation period and as the prosthesis ages (32). Despite their clinical success, prosthetic complications and maintenance with IODs are unavoidable. However, the complication rates and repair needs should be kept to a minimum, especially in elderly patients (31).

Patient satisfaction is a key factor for successful treatment. In the present study, most recruits were satisfied with the functionality and aesthetics of their prostheses, with more positive outcomes registered for the MA-IODs.
The ease of cleaning and minor peri-implant complications for the MA-IODs, as reported in the present study, may account for such findings. Although the recruits reported better retention and chewing function for the BA-IODs, the responses were not significantly different from those of the MA-IODs. Magnetic forces present in the MA-IODs are direction-dependent. Those forces are the strongest in the vertical dimension at the interface between the magnet and the metal base and are weakest in the lateral dimensions (11). In general, MA-IODs suffer from reduced resistance to lateral displacement during oral function. Hence, MAIODs do not perform as well as BA-IODs in terms of denture retention and chewing, especially in patients with severe alveolar ridge atrophy. Nevertheless, a previous study showed that the MA system performed similarly to other attachment systems in terms of masticatory efficiency (11). The MA system minimizes traumatic loads against the implant fixtures because of reduced resistance to lateral forces. It is also easier to maintain and clean than other attachment systems. These advantages render the MA system a useful therapeutic option for osteoporosis patients and for patients in whom mini-implants have to be used due to mandibular bony deficiency (33).

The Oral Health Impact Profile-14 questionnaire has 
also been used in related studies $(34,35)$. The questionnaire has been shown to be highly sensitive and accurate (36). In the present study, there were no differences in OHRQoL scores between MA-IODs and BA-MODs for any item examined. Consistent with the present findings, Mumcu et al. did not detect significant differences in OHRQoL scores based on the type of attachment system (37). Khalid et al. obtained higher OHRQoL scores for IODs compared with conventional non implant supported complete dentures; however, the authors did not find differences in OHRQoL scores between different IOD attachment systems (38). Although similar OHRQoL scores were obtained for both attachment systems, the null hypothesis tested in the present study still has to be rejected because other factors such as peri-implant health and the subjects' self-perception of functionality and esthetics are superior for the MA-IODs.

Longer observation periods and larger sample sizes are required for future studies. In the present study, the effect of opposing dentition, such as maxillary complete dentures, tooth supported removable partial dentures, IODs or natural teeth, was not considered. Because antagonistic dentition plays an important role in the retention of mandibular complete denture, the variability of the opposing dentition on denture retention should be studied in future research.

\section{Conclusions}

Within the limitations of the present study, the outcomes of this retrospective study show that IODs have desirable medium-term rehabilitation potential for the edentulous mandibular jaw. Both the BA and MA systems are useful in IODs, although the MA system performs marginally better in peri-implant health and hygienic maintenance than the BA system. Dentists are reminded to provide oral hygiene instructions and regular clinical examinations for patients wearing mandibular IODs.

\section{Acknowledgments}

Funding: This work was supported by the Open Project of State Key Laboratory of Military Stomatology (No. 2018KA02 to YJ), National Natural Science Foundation of China (81720108011 and 81470773 to JHC), and the program for Changjiang Scholars and Innovative Research Team in University (No. IRT13051 to JHC).

\section{Footnote}

Reporting Checklist: The authors have completed the STROBE reporting checklist. Available at http://dx.doi. org/10.21037/atm-20-2531

Data Sharing Statement: Available at http://dx.doi. org/10.21037/atm-20-2531

Conflicts of Interest: All authors have completed the ICMJE uniform disclosure form (available at http://dx.doi. org/10.21037/atm-20-2531). The authors have no conflicts of interest to declare.

Ethical Statement: The authors are accountable for all aspects of the work in ensuring that questions related to the accuracy or integrity of any part of the work are appropriately investigated and resolved. The study was conducted in accordance with the Declaration of Helsinki (as revised in 2013). The present study was approved by the Institutional Review Board of Stomatological Hospital of Fourth Military Medical University (approval number: IRB-REV-2016036). Informed consent was received from all the patients. Permission to access data for the study was obtained from Department of Prosthodontics, School of Stomatology, the Fourth Military Medical University, Xi'an, China.

Open Access Statement: This is an Open Access article distributed in accordance with the Creative Commons Attribution-NonCommercial-NoDerivs 4.0 International License (CC BY-NC-ND 4.0), which permits the noncommercial replication and distribution of the article with the strict proviso that no changes or edits are made and the original work is properly cited (including links to both the formal publication through the relevant DOI and the license). See: https://creativecommons.org/licenses/by-nc-nd/4.0/.

\section{References}

1. Kassebaum NJ, Bernabé E, Dahiya M, et al. Global Burden of Severe Tooth Loss: A Systematic Review and Meta-analysis. J Dent Res 2014;93:20S-28S.

2. Critchlow SB, Ellis JS. Prognostic indicators for conventional complete denture therapy: A review of the literature. J Dent 2010;38:2-9.

3. Hyland R, Ellis J, Thomason M, et al. A qualitative study on patient perspectives of how conventional and implant- 
supported dentures affect eating. J Dent 2009;37:718-23.

4. Brennan M, Houston F, O'Sullivan M, et al. Patient satisfaction and oral health-related quality of life outcomes of implant overdentures and fixed complete dentures. Int J Oral Maxillofac Implants 2010;25:791-800.

5. Reissmann DR, Dard M, Lamprecht R, et al. Oral healthrelated quality of life in subjects with implant-supported prostheses: A systematic review. J Dent 2017;65:22-40.

6. Sivaramakrishnan G, Sridharan K. Comparison of implant supported mandibular overdentures and conventional dentures on quality of life: a systematic review and metaanalysis of randomized controlled studies. Aust Dent J 2016;61:482-8.

7. Turkyilmaz I, Company AM, McGlumphy EA. Should edentulous patients be constrained to removable complete dentures? the use of dental implants to improve the quality of life for edentulous patients. Gerodontology 2010;27:3-10.

8. Nogueira TE, Aguiar FMO, Esfandiari S, et al. Effectiveness of immediately loaded single-implant mandibular overdentures versus mandibular complete dentures: A 1-year follow-up of a randomized clinical trial. J Dent 2018;77:43-50.

9. Passia N, Wolfart S, Kern M. Ten-year clinical outcome of single implant-retained mandibular overdentures-A prospective pilot study. J Dent 2019;82:63-5.

10. Sharka R, Abed H, Hector M. Oral health-related quality of life and satisfaction of edentulous patients using conventional complete dentures and implantretained overdentures: An umbrella systematic review. Gerodontology 2019;36:195-204.

11. Cheng T, Sun G, Huo J, et al. Patient satisfaction and masticatory efficiency of single implant-retained mandibular overdentures using the stud and magnetic attachments. J Dent 2012;40:1018-23.

12. Lehmann KM, Kämmerer PW, Karbach J, et al. Longterm effect of overdenture bar design on peri-implant tissues. Int J Oral Maxillofac Implants 2013;28:1126-31.

13. Boven GC, Meijer HJA, Vissink A, et al. Maxillary implant overdentures retained by use of bars or locator attachments: 1-year findings from a randomized controlled trial. J Prosthodont Res 2020;64:26-33.

14. Frisch E, Ziebolz D, Rinke S. Long-term results of implant-supported over-dentures retained by double crowns: A practice-based retrospective study after minimally 10 years follow-up. Clin Oral Implants Res 2013;24:1281-7.

15. Cepa S, Koller B, Spies BC, et al. Implant-retained prostheses: ball vs. conus attachments-a randomized controlled clinical trial. Clin Oral Implants Res 2017;28:177-85.

16. Elsyad MA, Mahanna FF, Elshahat MA, et al. Locators versus magnetic attachment effect on peri-implant tissue health of immediate loaded two implants retaining a mandibular overdenture: A 1-year randomised trial. J Oral Rehabil 2016;43:297-305.

17. Elsyad MA, Alokda MM, Gebreel AA, et al. Effect of two designs of implant-supported overdentures on periimplant and posterior mandibular bone resorptions: a 5 -year prospective radiographic study. Clin Oral Implants Res 2017;28:e184-92.

18. Boven GC, Meijer HJA, Vissink A, et al. Maxillary implant overdentures retained by use of bars or locator attachments: 1-year findings from a randomized controlled trial. J Prosthodont Res 2020;64:26-33.

19. Silness J, Löe H. Periodontal disease in pregnancy II. Correlation between oral hygiene and periodontal condition. Acta Odontol Scand 1964;22:121-35.

20. Eerdekens L, Schols M, Coelst L, et al. A 5-year prospective study on cone-anchored implants in the edentulous maxilla. Clin Implant Dent Relat Res 2015;17:e621-e632.

21. Quirynen M, Al-Nawas B, Meijer HJ, et al. Small-diameter titanium Grade IV and titanium-zirconium implants in edentulous mandibles: three-year results from a doubleblind, randomized controlled trial. Clin Oral Implants Res 2015;26:831-40.

22. Mombelli A, van Oosten MAC, Schürch E, et al. The microbiota associated with successful or failing osseointegrated titanium implants. Oral Microbiol Immunol 1987;2:145-51.

23. Vercruyssen M, Marcelis K, Coucke W, et al. Long-term, retrospective evaluation (implant and patient-centred outcome) of the two-implants-supported overdenture in the mandible. Part 1: Survival rate. Clin Oral Implants Res 2010;21:357-65.

24. Rinke S, Rasing H, Gersdorff N, et al. Implant-supported overdentures with different bar designs: A retrospective evaluation after 5-19 years of clinical function. J Adv Prosthodont 2015;7:338-43.

25. Behneke A, Behneke N, d'Hoedt B. A 5-year longitudinal study of the clinical effectiveness of ITI solid-screw implants in the treatment of mandibular edentulism. Int J Oral Maxillofac Implants 2002;17:799-810.

26. Cehreli MC, Karasoy D, Kökat AM, et al. A systematic review of marginal bone loss around implants retaining or supporting overdentures. J Prosthet Dent 2011;105:4. 
27. Cune MS, Burgers M, van Kampen FMC, et al. Mandibular overdentures retained by two implants: 10year results from a crossover clinical trial comparing ball-socket and bar-clip attachments. J Prosthet Dent 2011;105:136.

28. Kuoppala R, Näpänkangas R, Raustia A. Outcome of implant-supported overdenture treatment - A survey of 58 patients. Gerodontology 2012;29:e577-e584.

29. Wysowski DK, Green L. Serious adverse events in norplant users reported to the food and drug administration's medwatch spontaneous reporting system. Obstet Gynecol 1995;85:538-42.

30. Song SY, Kang KH, Lee JY, et al. Effects of type of magnet attachment and implant angulation in two implant overdenture models. J Adv Prosthodont 2020;12:33-7.

31. Assaf A, Daas M, Boittin A, et al. Prosthetic maintenance of different mandibular implant overdentures: A systematic review. J Prosthet Dent 2017;118:144-152.e5.

32. García-Minguillán G, Del Río J, Preciado A, et al. Impact of the retention system of implant fixed dental restorations on the peri-implant health, state of the prosthesis, and patients' oral health-related quality of life. J Dent 2020;94:103298.

33. Yang TC, Maeda Y, Gonda T, et al. Attachment systems

Cite this article as: Zhou H, Jiao Y, Ma CF, Wang C, Zhao SJ, Tian M, Tay FR, Chen JH. Clinical outcomes of implant-retained mandibular overdentures using the bar and magnetic attachment systems: an up to 5-year retrospective study. Ann Transl Med 2020;8(21):1360. doi: 10.21037/atm-202531 for implant overdenture: Influence of implant inclination on retentive and lateral forces. Clin Oral Implants Res 2011;22:1315-9.

34. de Souza RF, Ribeiro AB, Della Vecchia MP, et al. Mini vs. standard implants for mandibular overdentures: A randomized trial. J Dent Res 2015;94:1376-84.

35. Peršić S, Ćelić R, Vojvodić D, et al. Oral health-related quality of life in different types of mandibular implant overdentures in function longer than 3 years. Int J Prosthodont 2016;29:28-30.

36. Montero J, López JF, Vicente MP, et al. Comparative validity of the OIDP and OHIP-14 in describing the impact of oral health on quality of life in a cross-sectional study performed in Spanish adults. Med Oral Patol Oral Cir Bucal 2011;16:e816-21.

37. Mumcu E, Bilhan H, Geckili O. The effect of attachment type and implant number on satisfaction and quality of life of mandibular implant-retained overdenture wearers. Gerodontology 2012;29:e618-e623.

38. Khalid T, Yunus N, Ibrahim N, et al. Patient-reported outcome and its association with attachment type and bone volume in mandibular implant overdenture. Clin Oral Implants Res 2017;28:535-42. 